\title{
FORMULASI GEL EKSTRAK BATANG PEPAYA (Carica papaya Linn.) SERTA UJI ANTIBAKTERI TERHADAP Staphylococcus aureus ATCC 25923
}

\author{
${ }^{1 *}$ Muhammad Agus Ulil Albab, ${ }^{2}$ Amalia Eka Putri, ${ }^{3}$ Choirul Huda
}

1,2,3Program Studi S1 Farmasi, STIKes Karya Putra Bangsa, Tulungagung

Info Article
Submitted :
19 Agustus 2020
Revised :
13 Oktober 2020
Accepted :
26 November 2020
Corresponding Author:
Muhammad Agus Ulil
Albab
Email :
agusulil66@gmail.com

Antibiotik adalah salah satu terapi yang digunakan dalam menangani infeksi, akan tetapi penggunaan antibiotik sudah menjadi resistensi akibat penggunaan yang tidak tepat. Oleh karena itu, diperlukan adanya terapi alternatif dari tumbuhan yang berpotensi tinggi sebagai antibakteri. Tujuan penelitian ini adalah mengetahui stabilitas fisik dan aktivitas antibakteri sediaan gel ekstrak batang pepaya terhadap Staphylococcus aureus ATCC 25923 menggunakan metode difusi agar. Metode penelitian yang digunakan adalah eksperimental. Sampel batang papaya diekstraksi menggunakan metode maserasi dengan etanol $70 \%$. Kontrol positif menggunakan gel klindamisin dan kontrol negatif adalah basis gel tanpa ekstrak. Ekstrak batang pepaya dibuat menjadi sediaan gel dengan konsentrasi $5 \%, 10 \%$, dan $20 \%$. Sediaan gel dilakukan evaluasi meliputi uji organoleptis, $\mathrm{pH}$, homogenitas, daya sebar, daya lekat, dan daya proteksi selama 10 hari. Hasil pengujian aktivitas antibakteri gel ekstrak batang pepaya menunjukkan gel ekstrak batang pepaya mempunyai aktivitas antibakteri terhadap Staphylococcus aureus ATCC 25923. Gel ekstrak batang pepaya dengan konsentrasi 5\%; 10\%; dan $20 \%$ secara berurutan memiliki rata-rata zona hambat sebesar $19,7 \pm 0,721 \mathrm{~mm} ; 21,9 \pm 1,625 \mathrm{~mm}$; dan $23,6 \pm 1,629 \mathrm{~mm}$. Aktivitas antibakteri diduga berasal dari aktivitas senyawa flavonoid, tanin, dan saponin dalam ekstrak batang pepaya. Gel ekstrak batang pepaya memiliki daya hambat lebih kecil dibanding dengan gel klindamisin yang memiliki rata-rata zona hambat sebesar $28 \pm 0,577$ $\mathrm{mm}$. Gel esktrak batang pepaya memenuhi syarat uji organoleptis, homogentis, pH, daya sebar, daya lekat, dan daya proteksi serta stabil dalam masa penyimpanan.

Kata kunci: Antibakteri, gel, Carica papaya Linn, Staphylococcus aureus ATCC 25923

Access this article

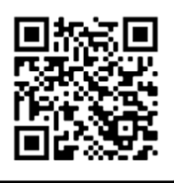

SCAN ME
ABSTRACT

Antibiotics are one of the therapies used to treat infections, but the use of antibiotics has become resistant due to inappropriate use. Therefore, it is necessary to have alternative therapies from plants that have high potential as antibacterial agents. The purpose of this study was to determine the physical stability and antibacterial activity of papaya stem extract gel against Staphylococcus aureus 
ATCC 25923 using the agar diffusion method. The research method used was experimental. Papaya stem samples were extracted using the maceration method with $70 \%$ ethanol. The positive control used clindamycin gel and the negative control was based on gel without extract. Papaya stem extract is made into gel preparations with a concentration of $5 \%, 10 \%$, and $20 \%$. The gel preparation was evaluated including the organoleptic test, $\mathrm{pH}$, homogeneity, dispersion, adhesion, and protection power for 10 days. The test results showed that the papaya stem extract gel had antibacterial activity against Staphylococcus aureus ATCC 25923. Papaya stem extract gel with a concentration of $5 \% ; 10 \%$; and $20 \%$, respectively, had an average zone of inhibition of $19.7 \pm 0.721 \mathrm{~mm} ; 21.9 \pm 1,625$ $\mathrm{mm}$; and $23.6 \pm 1,629 \mathrm{~mm}$. The antibacterial activity is thought to come from the activity of flavonoids, tannins and saponins in papaya stem extract. Papaya stem extract gel had less inhibition than clindamycin gel which had an average inhibition zone of $28 \pm$ $0.577 \mathrm{~mm}$. Papaya stem extract gel met the requirements for organoleptic, homogeneous, $\mathrm{pH}$, dispersion, adhesion, and protection and was stable during storage.

Keywords: Antibacterial, gel, Carica papaya Linn, Staphylococcus aureus ATCC 25923

\section{PENDAHULUAN}

Antibiotik telah digunakan selama 60 tahun untuk mengurangi angka kesakitan dan kematian karena penyakit infeksi (WHO, 2015). Awalnya resistensi hanya terjadi di lingkungan rumah sakit, namun semakin lama resistensi menjadi meluas ke lingkungan masyarakat, khususnya bakteri Staphylococcus aureus ATCC 25923 sehingga kemunculan resistensi antibiotik menjadi masalah global kesehatan masyarakat yang dihadapi dalam beberapa dekade terakhir (Kemenkes RI, 2011).

Obat herbal mulai banyak diminati oleh manyarakat luas. Tanaman yang dipakai sebagai obat herbal yaitu batang pepaya. Hasil dari uji fitokimia pada batang tanaman pepaya terdapat beberapa kandungan senyawa metabolit sekunder seperti saponin, antrakuinon, alkaloid, tannin, dan flavonoid. Senyawa metabolit sekunder dalam ekstrak etanol batang pepaya yang berperan dalam aktivitas antibakteri terhadap Staphylococcus aureus ATCC 25923 yaitu senyawa saponin (Simbolon, Yelmira, \& Faizal, 2018). Metode ekstraksi yang digunakan dalam penelitian ini yaitu maserasi dengan pelarut etanol 70\% karena senyawa saponin dan tanin cenderung mempunyai sifat polar, sedangkan flavonoid cenderung mempunyai sifat polar. Pelarut yang digunakan yaitu etanol $70 \%$ dengan tujuan agar senyawa saponin, tanin, dan flavonoid dapat terekstrak secara maksimal (Harborne, 2006).

Penelitian ini dilakuan untuk meneliti lebih lanjut tentang formulasi gel ekstrak etanol batang pepaya (Carica papaya Linn.) serta uji antibakteri terhadap bakteri Staphylococcus aureus ATCC 25923 yang merupakan bakteri gram positif. Penelitian ini dilakukan dengan menggunakan metode difusi padat cakram untuk mengetahui aktivitas antibakteri terhadap Staphylococcus aureus ATCC 25923. Hasil dari penelitian ini diharapkan dapat memberikan informasi dan pengetahuan terhadap masyarakat luas tentang obat- 
obatan tradisional yang saat ini masih berdasarkan pengelaman empiris.

\section{METODE PENELITIAN}

\subsection{Alat}

Alat yang digunakan dalam penelitian ini yaitu oven, ayakan mesh 80 , botol maserasi, pH universal, gelas objek, lempeng kaca, penggaris, stop watch, alat uji daya lekat, cawan porselen, kertas cakram, autoklaf (GEA YX2808), mikropipet, jangka sorong, inkubator (model DNP Electro Thermal Incubator), dan ose.

\subsection{Bahan}

Bahan yang digunakan dalam penelitian ini yaitu batang pepaya (Carica papaya Linn.) dalam kondisi segar sebanyak 5 kg, etanol 70\% sebanyak 5000 $\mathrm{mL}$, asam asetat glasial, asam sulfat $\left(\mathrm{H}_{2} \mathrm{SO}_{4}\right)$, magnesium $(\mathrm{Mg})$, asam klorida $(\mathrm{HCl})$, asam asetat anhidrat, larutan ferri klorida $\left(\mathrm{FeCl}_{3}\right)$ $1 \%$, CMC, gliserin, propilen glikol, nutrient agar (NA), aquadestilata, nutrient broth (NB), manitol salt agar (MSA), Staphylococcus aureus ATCC 25923, hydrogen peroksida, $\mathrm{NaCl}$ fisiologis, $\mathrm{Mc}$ Farland, dan klindamisin.

\subsection{Prosedur Penelitian}

\subsubsection{Pengambilan sampel penelitian}

Sampel yang digunakan dalam penelitian ini adalah batang pepaya (Carica papaya Linn.) berumur 9-12 bulan yang terdapat di kabupaten Blitar, Jawa Timur. Sampel penelitian yang telah melewati proses determinasi kemudian dilakukan sortasi kering dan basah. Sampel dipotong kecil-kecil hingga diperoleh ukuran yang sesuai dan dilakukan penimbangan. Pengeringan menggunakan oven dengan suhu sekitar $40-50^{\circ} \mathrm{C}$ sampai kering membentuk simplisia. Simplisia kemudian di blender untuk membentuk menjadi serbuk halus dan diayak dengan ayakan mesh 80.

\subsubsection{Metode ekstraksi}

Sampel diekstraksi dengan metode maserasi menggunakan pelarut etanol 96\%. Ekstrak kemudian dipekatkan.

\subsubsection{Skrining fitokimia}

\section{a. Flavonoid}

Sampel dilarutkan dengan $3 \mathrm{~mL}$ etanol kemudian dipanaskan dan disaring. Filtrat ditambah dengan $\mathrm{Mg} \mathrm{0,1} \mathrm{g}$ dan 2 tetes HCL pekat. Hasil positif mengandung flavonoid ditunjukkan dengan terbentuknya warna merah, orange, dan hijau (Baud, Sangi, \& Koleangan, 2014).

\section{b. Tanin}

Sampel dilarutkan dengan etanol kemudian ditambahkan dengan 2-3 tetes $\mathrm{FeCl}_{3} 1 \%$. Hasil positif mengandung tanin ditunjukkan dengan terbentuknya warna hitam kebiruan atau hijau (Harborne, 2006).

\section{c. Saponin}

Sampel dilarutkan dengan $10 \mathrm{~mL}$ aquadestilata kemudian dididihkan dalam penangas air. Larutan sampel kemudian dikocok dan didiamkan selama 15 menit. Hasil positif mengandung saponin ditunjukkan dengan terbentuknya busa stabil (bertahan lama) (Harborne, 1987).

\subsubsection{Pembuatan sediaan gel}

Disiapkan semua bahan yang akan digunakan yaitu ekstrak batang pepaya (5\%, 10\%, dan 20\%), CMC 3 g, gliserin 10 $\mathrm{mL}$, dan propilenglikol $5 \mathrm{~mL}$. Ekstrak dengan konsentrasi 5\% dilarutkan dalam sebagian air yang telah dipanaskan pada suhu $50^{\circ} \mathrm{C}$. Ditambah CMC $3 \mathrm{~g}$ dan diaduk sampai homogen. Kemudian menambahkan gliserin $10 \mathrm{~mL}$, propilenglikol $5 \mathrm{~mL}$, dan air sampai volume $100 \mathrm{~mL}$ dengan pengandukan secara 
kontinyu hingga terentuk gel. Gel yang telah terbentuk kemudian disimpan pada suhu ruangan. Prosedur yang sama juga dilakukan pada ekstrak dengan konsentrasi 10\% dan 20\% (Aponno, Yamlean, \& Supriati, 2014).

Tabel 1. Formula sediaan gel

\begin{tabular}{lccc}
\hline \multirow{2}{*}{ Bahan } & \multicolumn{3}{c}{ Konsentrasi Gel } \\
\cline { 2 - 4 } & F.I & F.II & F.III \\
\hline Ekstrak Batang & $5 \mathrm{~g}$ & $10 \mathrm{~g}$ & $20 \mathrm{~g}$ \\
Pepaya & $3 \mathrm{~g}$ & $3 \mathrm{~g}$ & $3 \mathrm{~g}$ \\
CMC & $10 \mathrm{~mL}$ & $10 \mathrm{~mL}$ & $10 \mathrm{~mL}$ \\
Gliserin & $5 \mathrm{~mL}$ & $5 \mathrm{~mL}$ & $5 \mathrm{~mL}$ \\
Propilenglikol & $100 \mathrm{~mL}$ & $100 \mathrm{~mL}$ & $100 \mathrm{~mL}$ \\
Aquadestilata ad & \multicolumn{3}{c}{} \\
\hline
\end{tabular}

\subsubsection{Uji evaluasi sediaan gel}

\section{a. Uji organoleptis}

Uji organoleptis dilakukan secara visusal dan dilihat secara langsung bentuk, warna, dan bau dari sedian gel. Gel yang baik yaitu gel yang jernih dengan konsistensi setengah padat (Ansel, 1989).

\section{b. Uji pH}

Sediaan gel ditimbang sebanyak 1 gram dan dilarutkan dalam $100 \mathrm{~mL}$ akuadestilata dalam gelas beker. Larutan diukur $\mathrm{pH}$-nya menggunakan $\mathrm{pH}$ indikator universal sebanyak tiga kali replikasi dan dihitung nilai rata-rata $\mathrm{pH}$, (Kaur \& Guleri, 2007). Digunakan untuk mengetahui $\mathrm{pH}$ gel, apakah sesuai dengan $\mathrm{pH}$ kulit yaitu 56,5 (Voight, 1984).

\section{c. Uji homogenitas}

Diambil sediaan gel secukupnya, dioleskan pada gelas objek kemudian diraba dan digosok. Diamati susunan sedian pada gelas objek. Massa gel homogen ditunjukkan dengan tidak adanya bahan padat atau butiran pada kaca (Dewantari \& Sugihartini, 2015).

\section{d. Uji daya sebar}

Sediaan ditimbang sebanyak 500 mg, diletakkan ditengah kaca bulat berskala dan diletakkan kaca bulat lainnya yang telah ditimbang diatas gel selama 1 menit. Diukur diameter gel yang menyebar, kemudian ditambahkan beban $50 \mathrm{~g}$ didiamkan selama 1 menit. Dicatat diameter gel yang menyebar dan setelah penambahan beban $100 \mathrm{~g}, 150 \mathrm{~g}$, dan 200 g. Daya sebar gel yang baik antara $5-7 \mathrm{~cm}$ (Dewantari \& Sugihartini, 2015).

\section{e. Uji daya lekat}

Sampel gel sebanyak 0,25 g diletakkan diantara 2 objek glass pada alat uji daya lekat, ditekan dengan beban $1 \mathrm{~kg}$ selama 5 menit, kemudian beban diangkat dan pada alat uji dilepaskan beban $80 \mathrm{~g}$ serta dicatat waktu pelepasan gel. Sediaan gel yang baik memiliki waktu daya lekat lebih dari 4 detik (Dewantari \& Sugihartini, 2015).

\section{f. Uji daya proteksi}

Sediaan gel dioleskan pada kertas saring yang sebelumnya telah ditetesi fenoftalein. Kertas tersebut ditempelkan pada kertas saring lain dan kemudian ditetesi larutan $\mathrm{KOH} \quad 0,1 \quad \mathrm{~N}$. Diamati munculnya warna merah pada waktu detik ke 15, 30, 45, 60 serta menit ke 3 dan 5 . Gel yang baik tidak muncul bercak merah pada kertas saring (Widyantoro \& Sugihartini, 2015).

\subsubsection{Uji aktivitas antibakteri}

Uji aktivitas antibakteri fraksi batang pepaya dilakukan menggunakan metode difusi cakram. Kertas cakram steril yang telah diresapi gel ekstrak batang pepaya masing-masing dengan konsentrasi $1 \%$ tanpa pengenceran, ditempatkan pada permukaan media agar NA yang telah diinokulasikan Staphylococcus aureus ATCC 25923. Kontrol positif menggunakan gel klindamisin tanpa pengenceran. Kontrol negatif menggunakan sediaan gel tanpa ekstrak. Selanjutnya diinkubasi pada suhu 
$37^{\circ} \mathrm{C}$ selama 24 jam. Hasil diamati dan diukur diameter zona hambat yang terbentuk. Data yang didapatkan kemudian dilakukan analisis statistik.

\section{HASIL DAN PEMBAHASAN}

Hasil determinasi tanaman menunjukkan bahwa sampel yang digunakan adalah benar batang dari tanaman pepaya (Carica papaya Linn.). Uji kadar air pada simplisia batang pepaya mendapatkan hasil yaitu kadar air sebesar $9,3 \%$ yang berarti kurang dari $10 \%$. Syarat kadar air pada serbuk simplisia yaitu kurang dari $10 \%$ agar reaksi enzimatik tidak dapat berlangsung sehingga simplisia dapat tahan lama dan zat aktif tidak berubah (Departemen Kesehatan RI, 2011). Simplisia batang pepaya yang diekstraksi dengan metode maserasi menghasilkan ekstrak etanol batang pepaya dengan rendemen sebesar 20,2\%. Hasil determinasi tanaman, uji kadar air, dan ekstraksi, disajikan pada Tabel 2.

Tabel 2. Hasil determinasi tanaman, uji kadar air, dan ekstraksi.

\begin{tabular}{|c|c|c|c|}
\hline No. & Perlakuan & Sampel & Hasil \\
\hline 1. & $\begin{array}{l}\text { Determinasi } \\
\text { Tanaman }\end{array}$ & $\begin{array}{l}\text { Batang } \\
\text { pepaya }\end{array}$ & $\begin{array}{l}\text { Batang } \\
\text { pepaya } \\
\text { (Carica } \\
\text { papaya Linn.) }\end{array}$ \\
\hline 2. & $\begin{array}{l}\text { Uji Kadar Air } \\
\text { Simplisia }\end{array}$ & $\begin{array}{l}\text { Serbuk } \\
\text { simplisia } \\
\text { batang } \\
\text { pepaya }\end{array}$ & $8,7 \%$ \\
\hline 3. & $\begin{array}{l}\text { Rendemen } \\
\text { Ekstrak }\end{array}$ & $\begin{array}{l}\text { Ekstrak } \\
\text { batang } \\
\text { pepaya }\end{array}$ & $5,76 \%$ \\
\hline
\end{tabular}

Skrining fitokimia pada ekstrak batang pepaya bertujuan untuk mengetahui atau memastikan keberadaan dari senyawa-senyawa metabolit sekunder yang terkandung di dalam ekstrak tersebut. Batang dari tanaman pepaya mempunyai kandungan kimia antara lain saponin, tanin, dan flavonoid (Warisno, 2003). Menurut penelitian Simbolon (2018), senyawa aktif pada ekstrak batang pepaya yang memiliki aktivitas sebagai antibakteri yaitu golongan senyawa flavonoid, tanin, dan saponin. Hasil dari skrining fitokimia ekstrak batang pepaya ditunjukkan pada Tabel 3.

Tabel 3. Skrining fitokimia

\begin{tabular}{lccc}
\hline \multirow{2}{*}{ Sampel } & \multicolumn{3}{c}{ Skrining Fitokimia } \\
\cline { 2 - 4 } & Flavonoid & Tanin & Saponin \\
\hline Ekstrak & $\sqrt{ }$ & $\sqrt{ }$ & $\sqrt{ }$ \\
Batang & $\sqrt{ }$ & & \\
Pepaya & & & \\
\hline
\end{tabular}

Uji stabilitas sediaan gel meliputi uji organoleptis, uji homogenitas, uji $\mathrm{pH}$, uji daya sebar, uji daya lekat, dan uji daya proteksi.

Uji organoleptis gel ekstrak batang pepaya $\mathrm{Fl}, \mathrm{Fll}$, dan FIII memiliki bau khas batang papaya, berbentuk semi solid, dan berwarna coklat kehitaman.

Uji homogenitas gel ekstrak batang pepaya FI, FII, dan FIII dilakukan uji sebanyak $3 x$ kemudian diambil rat-rata. Hasil yang didapat homogen, karena tidak terdapat bahan padat atau butiran pada kaca.

Uji pH gel ekstrak batang pepaya $\mathrm{Fl}$, FII, dan FIII dilakukan uji sebanyak $3 x$ kemudian diambil rat-rata. Hasil yang didapat memiliki pH 6, yang berarti sesuai dengan pH kulit yaitu antara 5- 6,5.

Uji daya sebar gel ekstrak batang pepaya FI, FII, dan FIII dilakukan uji sebanyak $3 x$ kemudian diambil rat-rata. Hasil yang didapat berturut turut yaitu 5,06 $\mathrm{cm}, 5,13 \mathrm{~cm}$, dan $5,1 \mathrm{~cm}$, yang berarti memiliki daya sebar gel yang baik, karena 
gel yang baik memiliki daya sebar antara 5$7 \mathrm{~cm}$.

Uji daya lekat gel ekstrak batang pepaya FI, FII, dan FIII dilakukan uji sebanyak $3 x$ kemudian diambil rat-rata. Hasil yang didapat berturut turut yaitu 7,37 detik, 7,8 detik, dan 7,6 detik, yang berarti memiliki daya lekat gel yang baik, karena gel yang baik memeiliki daya lekat lebih dari 4 detik.

Uji daya proteksi gel ekstrak batang pepaya FI, FII, dan FIII dilakukan uji sebanyak $3 x$ kemudian diambil rat-rata. Hasil yang didapat tidak timbul noda bercak merah, yang berarti sediaan gel memiliki kestabilan yang baik selama penyimpanan. Jika ada bercak merah berarti gel mengandung pengotor atau benda asing yang dapat mempengaruhi kestabilan gel.

Hasil uji aktivitas antibakteri pada kontrol positif menggunakan Gel klindamisin memiliki rata-rata zona hambat $28 \mathrm{~mm}$ yang artinya berada dalam rentang kategori zona hambat (sangat kuat). Hasil diameter zona hambat gel ekstrak batang pepaya $5 \%$ memiliki ratarata sebesar 19,7 $\mathrm{mm}$ yang termasuk dalam kategori zona hambat (kuat). Hasil diameter zona hambat gel ekstrak batang pepaya $10 \%$ memiiki rata-rata sebesar 21,9 $\mathrm{mm}$ termasuk kedalam kategori zona hambat (sangat kuat). Dan diameter zona hambat rata-rata gel ekstrak batang pepaya $20 \%$ sebesar 23,6 $\mathrm{mm}$ termasuk kedalam kategori zona hambat (sangat kuat). Dari hasil uji antibakteri gel ekstrak batang pepaya dengan konsenstrasi $10 \%$ dan 20\% sama-sama memiliki kategori sangat kuat, yang berarti gel ekstrak batang pepaya yang paling efektif yaitu gel dengan konsentrasi $10 \%$ karena dengan konsentrasi kecil sudah termasuk kategori sangat kuat. hasil tersebut dapat terjadi karena sebagian besar senyawa metabolit sekunder yg memiliki aktivitas antibakteri terhadap Staphylococcus aureus ATCC 25923 seperti flavonoid tanin dan saponin bersifat polar sehingga dapat larut maksimal dalam pelarut polar. Hasil tersebut juga didukung oleh penelitian yang dilakukan oleh Simbolon (2018) ekstrak etanol batang pepaya dibuat seri konsentrasi sebesar 1,5\% dan 3\%. Hasil penelitian menunjukkan bahwa pada kadar 1,5\% dan 3\% ekstrak etanol batang pepaya sudah mampu menghambat pertumbuhan bakteri Staphylococcus aureus ATCC 25923 dengan zona hambat sebesar 14,0 $\mathrm{mm}$ dan $15,0 \mathrm{~mm}$ yang termasuk kategori kuat. . Hasil uji aktivitas antibakteri pada gel ekstrak batang pepaya ditunjukkan pada Tabel 4.

Tabel 4. Hasil uji aktivitas antibakteri gel ekstrak batang pepaya

\begin{tabular}{|c|c|c|c|c|c|}
\hline \multirow{2}{*}{ No. } & \multirow{2}{*}{ Sampel } & \multicolumn{3}{|c|}{$\begin{array}{l}\text { Diameter Zona } \\
\text { Hambat (mm) }\end{array}$} & \multirow{2}{*}{$\begin{array}{l}\text { Rata } \\
\text { rata } \\
(\mathrm{mm}) \pm \\
\text { SD }\end{array}$} \\
\hline & & I & II & III & \\
\hline 1. & $\begin{array}{l}\text { Gel } \\
\text { ekstrak } \\
\text { batang } \\
\text { pepaya } \\
5 \%\end{array}$ & 18,3 & 19,7 & 19,7 & $\begin{array}{c}19,7 \pm \\
0,72\end{array}$ \\
\hline 2. & $\begin{array}{l}\text { Gel } \\
\text { ekstrak } \\
\text { batang } \\
\text { pepaya } \\
10 \%\end{array}$ & 20 & 23 & 21,9 & $\begin{array}{c}21,9 \pm \\
1,65\end{array}$ \\
\hline 3. & $\begin{array}{l}\text { Gel } \\
\text { ekstrak } \\
\text { batang } \\
\text { pepaya } \\
20 \%\end{array}$ & 21,7 & 24,3 & 23,6 & $\begin{array}{c}23,6 \pm \\
1,63\end{array}$ \\
\hline 4. & $\begin{array}{l}\text { Kontrol } \\
\text { positif }\end{array}$ & 28,3 & 28,3 & 28 & $\begin{array}{c}28,2 \pm \\
0,17\end{array}$ \\
\hline
\end{tabular}




\begin{tabular}{lllll} 
5. $\begin{array}{c}\text { Kontrol } \\
\text { negatif }\end{array}$ & 0 & 0 & 0 & $\begin{array}{c}0,00 \pm \\
0,00\end{array}$ \\
\hline
\end{tabular}

Berdasarkan data hasil uji antibakteri, dilakukan analisis statistik dengang SPSS 16 meliputi uji normalitas dengan metode shapiro-wilk yang menghasilkan signifikansi $0,000(<0,05)$ sehingga dapat disimpulkan bahwa data tidak terdistribusi normal. Selanjutnya dilakukakn uji statistic non parametric dengan uji kruskal-wallis yang menghasilkan signifikansi 0,011 $(<0,05)$ yang berarti terdapat perbedaan efek antibakteri yang signifikan antar kelompok perlakuan terhadap zona hambat yang dihasilkan. Kemudian dilanjutkan uji mann-whitney dengan hasil seluruhnya $<0,05$ yang berarti ada perbedaan rata rata antar kelompok perlakuan. Hasil ini sesuai karena ketiga seri konsentrasi gel ekstrak batang papaya belum ada yang menghasilkan aktivitas antibakteri setara dengan kontrol positif.

\section{KESIMPULAN}

Gel ekstrak batang pepaya (Carica papaya Linn) memiliki stabilitas sediaan yang baik selama masa penyimpanan. Gel ekstrak batang pepaya yang paling efektif yaitu konsentrasi 10\%, karena dengan konsentrasi kecil sudah termasuk dalam kategori sangat kuat yang diujikan terhadap bakteri Staphylococcus aureus ATCC 25923 dibandingkan dengan gel elstrak batang pepaya 5\% dan gel ekstrak batang pepaya $20 \%$.

\section{UCAPAN TERIMA KASIH}

Terima kasih kepada STIKes Karya Putra Bangsa Tulungagung, dan Bapak/lbu pembimbing yang telah membimbing dan membantu penelitian ini.

\section{DAFTAR PUSTAKA}

Ansel, H.C. (1989). Pengantar Bentuk Sediaan Farmasi, Edisi keempat. Jakarta : UI Press.

Aponno, J, V., Yamlean, P. V. Y., Supriati,H. S. (2014). Uji Efektivitas Sediaan Gel Ekstrak Etanol Daun Jambu Biji (Psidium guajava Linn) Terhadap Penyembuhan Luka yang Terinfeksi Bakteri Staphylococcus aureus pada Kelinci (Orytolagus cuniculus). PHARMACON Jurnal Ilmiah Farmasi.

Baud, G.S., Sangi, M.S., dan Koleangan, H.S.J. (2014). Analisis Senyawa Metabolit Sekunder dan Uji Toksisitas Ekstrak Etanol Batang Tanaman Patah Tulang (Euphorbia tirucalli L.) dengan Metode Brine Shrimp Lethality Test (BSLT). Journal Ilmiah Sains. Vol. 14(2). Hal. 106112.

Departemen Kesehatan Republik Indonesia. (2011). Farmakope Herbal Indonesia, Edisi I. Jakarta : Departemen Kesehatan RI. Hal. 110-111.

Dewantari, D.R. dan Sugihartini, N. (2015). Formulasi dan Uji Aktivitas Gel Ekstrak Daun Petai Cina (Leucaena glauca, Benth) sebagai Sediaan Obat Luka Bakar. Farmasains. Vol. 2(5): 217-222.

Harborne, J.B. (1987). Metode Fitokimia Penuntun Cara Modern Menganalisis Tumbuhan. Bandung: Penerbit ITB.

Harborne, J.B. (2006). Metode Fitokimia Penuntun Cara Modern Menganalisis Tumbuhan, Edisi Kedua. Bandung : ITB.

Kaur, L.P. and Guleri, T.K. (2013). Topical Gel: A Recent Approach for Novel Drug delivery, J.Biopharm.

KEMENKES RI. (2011). Buletin Jendela Data dan Informasi Kesehatan, Jakarta: Kementrian Kesehatan RI.

Simbolon, M., Yelmira Z., dan Faizal H. (2018). Pembuatan Sabun Transparan dengan Penambahan Ekstrak Batang Pepaya Sebagai Antibakteri. Chempublish Journal. Vol.3, Hal. 57-68.

Voigt. (1984). Buku Ajar Teknologi Farmasi. Yogyakarta : UGM Press. Hal: 337-338

Warisno. (2003). Budidaya Pepaya. Yogyakata : Kanisius.

WHO. (2015). World Health Statistic Report 2015. Geneva: World Halth Organization.

Widyantoro O.B. dan Sugihartini N. Uji sifat fisik dan aktivitas ekstrak daun petai cina 
(Laucaena glauca, benth) dalam berbagai

Fakultas Farmasi Universitas Ahmad tipe basis salep sebagai obat luka bakar.

Dahlan. (2015); 12(2): 186-9

Copyright $\odot 2020$ The author(s). You are free to Share - copy and redistribute the material in any medium or format. Adapt - remix, transform, and build upon the material. Under the following terms: Attribution - You must give appropriate credit, provide a link to the license, and indicate if changes were made. You may do so in any reasonable manner, but not in any way that suggests the licensor endorses you or your use. NonCommercial - You may not use the material for commercial purposes. ShareAlike - If apply legal terms or technological measures that legally restrict others from doing anything the license permits. 